\title{
Hepatoprotective properties of fennel seeds extract
}

\begin{abstract}
Hepatoprotective activity of fennel seeds extract was evaluated on male Wistar rats of 3 mon age. Rats were divided in to 13 groups each containing six rats. Group-I was maintained as normal control. Hepatotoxicity was induced with Carbon tetrachloride $1 \mathrm{ml} / \mathrm{kg}$ s.c. subcutaneously in rats of group II. Group-III rats were given standard drug Silymarin@100mg/kg along with CC14. Rats of Group IV-XIII were given CCL4 ( $1 \mathrm{ml} / \mathrm{kg}$, s.c.) Plus methanol and hexane extract of fennel $(400 \mathrm{mg} / \mathrm{kg} / \mathrm{bw}$, p.o.). Increased levels of ALT, AST, ALP, Bilirubin total and bilirubin direct in blood serum of treated rats were found to reduced by administration of seed extract of different fennel genotypes. Hepatoprotective effect was more evident in total bilirubin and ALP levels where seed extracts of both AF 1 and GF 1 were found to reduce total bilirubin content up to 0.42 and 0.38 respectively from 2.64. Level of ALP was also found to reduce up to 229.15 in hexane extract of genotype RF-101. Similar effect was observed from direct bilirubin content. Hexane seed extract was found more effective than methanol seed extract. A significant genotypic variation was also observed suggested that specific genotypes may be identified to be use for medicinal significance.
\end{abstract}

Volume 6 Issue I - 2018

Agarwal D, Saxena SN, Vishal MK, Sharma LK, Dubey PN, Agarwal A, Lal G

ICAR National Research Centre on Seed Spices, Pacific University, India

Correspondence: Saxena SN, ICAR National Research Centre on Seed Spices, Pacific University, Udaipur-3 I300 I, Tabiji, Ajmer-305206, India, Email shail.nrcss@gmail.com

Received: October 31, 2017 | Published: January 12, 2018

Keywords: bilirubin, carbon tetrachloride, foeniculum vulgare, hepatoprotective, rats

Abbreviations: OECD, organization for economic cooperation and development; CPCSEA, committee for the purpose of control and supervision of experiments on animals; GLM, general linear model; SGOT, serum glutamate oxaloacetate transaminase; ALP, alkaline phosphates

\section{Introduction}

Foeniculum vulgare, universally known as Fennel is an important seed spice crop belonging to the umbelliferae (Apiaceae) family. Fennel is very well known by ancient people of Europe and Asia Minor for its flavour and medicinal properties. Depending on the variety it may be an annual, biennial or perennial herb. Survey of published literature revealed that significant research work have been carried out on various aspects of its cultivation (propagation), nutritive value, uses, phytochemistry and pharmacology of seeds and green herbs as well as toxicity of $F$. Vulgare. ${ }^{1}$ Fennel has been known to controls many infectious disorders of microorganism origin. ${ }^{2-5}$ Seeds and essential oil of fennel has been reported to possess antioxidant, antitumor, chemopreventive, cytoprotective, hepatoprotective, hypoglycemic, and oestrogenic activities. ${ }^{1}$ In India fennel is cultivated in semi arid regions of Gujarat and Rajasthan states with an area of 760lakh hectares and production of 129350 tonnes annually (Spice board, India). Fennel seeds, whole and ground are important constituent of most of the curry powders in India and sub continent. Fennel seeds form major part of all kind of pickles due to its anti-microbial and preservative properties. ${ }^{1}$

A significant genetic variation for essential oil, total oil and phenolic compounds and antioxidant properties of available fennel germplasm has been reported by Saxena et $a .^{6}$ A systematic crop improvement programme which included development of new high yielding varieties is being going on at ICAR-NRCSS, Ajmer and AICRP on Spices, Calicut. A good number of varieties have been developed and released for fennel growing areas. These released fennel varieties may also show variation in its reported medicinal properties including hepatoprotective activity. Hence, a study was conducted to investigate variation in popular fennel varieties for its hepatoprotective activities using Wistar rats. Crude seed extract of five fennel genotypes in methanol and hexane extract have been evaluated and obtained results are being presented and discussed in this manuscript.

\section{Materials and methods}

\section{Preparation of seeds extracts}

Seeds of genotypes AF-1 (Ajmer Fennel-1), RF-1 (Rajasthan Fennel-1), GF-2 (Gujarat Fennel-2), Rajendra Saurabha and Hisar Swarup were obtained from NAGS of ICAR-NRCSS, Ajmer. The dried seeds $(30 \mathrm{gm})$ of each variety were ground to fine powders separately by milling. The resulting materials were extracted with hexane and methanol. After filtering the powder was again left in $5 \mathrm{ml}$ of different solvent for further extraction. Both the supernatant of solvent were pooled together. Solvent was evaporated using flesh evaporator (JSGW, Ambala, India). Crude extract was collected and stored at low temperature for further use.

\section{Acute oral toxicity- acute toxic class method}

The acute oral toxicity was carried out as per the guidelines set by Organization for Economic cooperation and Development (OECD), revised draft guidelines 423, received from Committee for the Purpose of Control and Supervision of Experiments on Animals (CPCSEA), Ministry of Social justice and Empowerment, Government of India. The principle is based on a stepwise procedure with the use of a minimum number of animals per step to obtain sufficient information on the acute toxicity of the test substance to enable its classification. The animals were divided into thirteen groups of six Wistar albino rats 
each and fasted for 24hours prior to carbon tetrachloride treatment Group-I was maintained as normal control received vehicle. Carbon tetrachloride dose were prepared with addition of $1 \mathrm{ml}$ of olive oil at 1:1 and given at two successive days to all animals of group. GroupII was given only $\mathrm{CCL}_{4} 1 \mathrm{ml} / \mathrm{kg}$ subcutaneously. Group-III received $\mathrm{CCL}_{4}$ plus standard drug Silymarin@100mg/kg. Rats of Group IVXIII were given $\mathrm{CCL}_{4}(1 \mathrm{ml} / \mathrm{kg}$, s.c.) Plus methanol and hexane extract of fennel $(400 \mathrm{mg} / \mathrm{kg} / \mathrm{bw}$, p.o.)

The animals of all groups were scarified by light ether anaesthesia on $6^{\text {th }}$ day. The blood sample of each animal was collected separately by carotid artery. Serum was separated by centrifugation at $3000 \mathrm{rpm}$ for 15 minutes and used to estimate serum glutamate pyruvate transaminase (SGPT), serum glutamate oxaloacetate transaminase (SGOT), Serum alkaline phosphates (ALP), serum direct and total bilirubin.

\section{Statistical analysis}

Effect of all treatments with control has been tested by General Linear Model (GLM) procedure using SAS 9.3 version. Tuckey post hoc test was employed where a significant difference was detected to determine between which treatments and control differed.

\section{Results and discussion}

Effect of fennel seed extracts on serum levels of AST, ALT, ALP and bilirubin of rates treated with $\mathrm{CCL}_{4}$ are presented in Table 1. The $\mathrm{CCL}_{4}$ administration resulted in increased levels of ALT, AST, ALP, Bilirubin total and bilirubin direct in blood serum of treated rats. Seed extract of different fennel genotypes were, however, reduced levels of ALT and AST as compared to the rats group of $\mathrm{CCL}_{4}$ induced liver injury but none of the seed extracts were at par with standard drug silymarin. Seed extract of genotypes AF-1 and GF-1 was most effective. Hepatoprotective effect was more evident in total bilirubin and ALP levels where seed extracts of both AF-1 and GF-1 were found to reduce total bilirubin content up to 0.42 and 0.38 respectively from 2.64. Similar effect was observed from direct bilirubin content. Hexane extract was more effective than methanol extract. Level of ALP was also found to reduce up to 229.15 in hexane extract of genotype RF101. Tuckey post hoc test was employed where a significant difference was detected to determine between which treatments and control differed. Figure 1 to be showed comparison of the effect of different treatments (crude seed extracts in methanol and hexane) with control (healthy mice) and $\mathrm{CCL}_{4}$ treated mice. Grouping of treatment is also shown in Table1 with value. Treatments with same letter notations in superscript are not significantly different. Treatments combinations which are touching the diagonal line in Figures 1-5 are not significant.

The value of ALT was at par (234.82) in control (44.67) and silymarin treated (46.64) mice. Figure 1 showed no significant differences among treatment 4, 5, 8, 9, 10 and 13 . Similarly methanol and hexane seed extract of Hisar Swarup and Rajendra Saurbha (T-6, 7, 11 and 12) also produced same results. None of the extract showed results near to either control or standard drug silymarin.

Methanol and hexane crude seed extract of genotypes AF-1, GF-2 and RF-101(T-4, 5, 8, 9, 10 and 13) produced similar results for SGOT content (Table 1) (Figure 2) as well as seed extract of Hisar Swarup and Rajendra Saurbha (T-6, 7, 11 and 12) also resulted with no significant difference. However, both the group of genotypes differs significantly. None of the treatment showed at par results with either control or standard drug silymarin but T-4, 5, 8, 9, 10 and 13 were found more effective than T-6, 7, 11 and 12 .

Table I Effect of fennel seed extracts on serum levels of AST,ALT,ALP and Bilirubin of rates treated with $\mathrm{CCL}_{4}$

\begin{tabular}{lllllll}
\hline Group & Treatment & $\begin{array}{l}\text { ALT or } \\
\text { SGPT } \\
(\mathbf{I U} / \mathbf{L})\end{array}$ & $\begin{array}{l}\text { AST or } \\
\text { SGOT } \\
(\mathbf{I U} / \mathbf{L})\end{array}$ & $\begin{array}{l}\text { Bilirubin } \\
\text { total }(\mathbf{m g} / \\
\mathbf{d l})\end{array}$ & $\begin{array}{l}\text { Bilirubin } \\
\text { direct } \\
\text { dl) }\end{array}$ & $\begin{array}{l}\text { ALP } \\
(\mathbf{I U} / \mathbf{L})\end{array}$ \\
\hline 1 & Control & $44.67^{\mathrm{E}}$ & $37.46^{\mathrm{F}}$ & $0.12^{\mathrm{F}}$ & $0.07^{\mathrm{L}}$ & $108.18^{\mathrm{E}}$ \\
2 & CCL $_{4}$ & $234.82^{\mathrm{A}}$ & $220.34^{\mathrm{A}}$ & $2.47^{\mathrm{A}}$ & $0.41^{\mathrm{A}}$ & $323.40^{\mathrm{A}}$ \\
3 & Silymarin & $46.64^{\mathrm{E}}$ & $47.66^{\mathrm{F}}$ & $0.14^{\mathrm{F}}$ & $0.10^{\mathrm{K}}$ & $191.87^{\mathrm{D}}$ \\
4 & AF-1 M & $210.12^{\mathrm{D}}$ & $178.29^{\mathrm{DE}}$ & $0.49^{\mathrm{E}}$ & $0.30^{\mathrm{E}}$ & $231.27^{\mathrm{C}}$ \\
5 & GF-2 M & $214.65^{\mathrm{DC}}$ & $181.20^{\mathrm{D}}$ & $0.45^{\mathrm{E}}$ & $0.27^{\mathrm{G}}$ & $229.74^{\mathrm{C}}$ \\
6 & H Swarop M & $227.29^{\mathrm{B}}$ & $201.66^{\mathrm{C}}$ & $1.73^{\mathrm{B}}$ & $0.39^{\mathrm{B}}$ & $278.30^{\mathrm{B}}$ \\
7 & R. Saurbha M & $226.95^{\mathrm{B}}$ & $206.14^{\mathrm{BC}}$ & $1.64^{\mathrm{BC}}$ & $0.33^{\mathrm{D}}$ & $277.79^{\mathrm{B}}$ \\
8 & RF-101 M & $216.62^{\mathrm{C}}$ & $176.32^{\mathrm{DE}}$ & $0.73^{\mathrm{D}}$ & $0.22^{\mathrm{I}}$ & $230.45^{\mathrm{C}}$ \\
9 & AF-1 H & $213.40^{\mathrm{DC}}$ & $180.26^{\mathrm{DE}}$ & $0.42^{\mathrm{E}}$ & $0.28^{\mathrm{F}}$ & $233.27^{\mathrm{C}}$ \\
10 & GF-2 H & $218.46^{\mathrm{C}}$ & $176.82^{\mathrm{DE}}$ & $0.38^{\mathrm{E}}$ & $0.20^{\mathrm{J}}$ & $231.93^{\mathrm{C}}$ \\
11 & H Swarop H & $226.15^{\mathrm{B}}$ & $207.12^{\mathrm{B}}$ & $1.58^{\mathrm{C}}$ & $0.37^{\mathrm{C}}$ & $279.24^{\mathrm{B}}$ \\
12 & R Saurbha H & $225.73^{\mathrm{B}}$ & $207.34^{\mathrm{B}}$ & $1.70^{\mathrm{B}}$ & $0.37^{\mathrm{C}}$ & $277.20^{\mathrm{B}}$ \\
13 & RF-101 H & $215.80^{\mathrm{C}}$ & $175.31^{\mathrm{E}}$ & $0.69^{\mathrm{D}}$ & $0.25^{\mathrm{H}}$ & $229.72^{\mathrm{C}}$ \\
SEM & & 17.28 & 20.55 & 0.009 & 0.00045 & 47.06 \\
\hline
\end{tabular}

Treatment means with same superscript letters are not significantly different test separately (i.e. for ALT, SGOT, Bilirubin Total, Bilirubin Direct and ALP. 


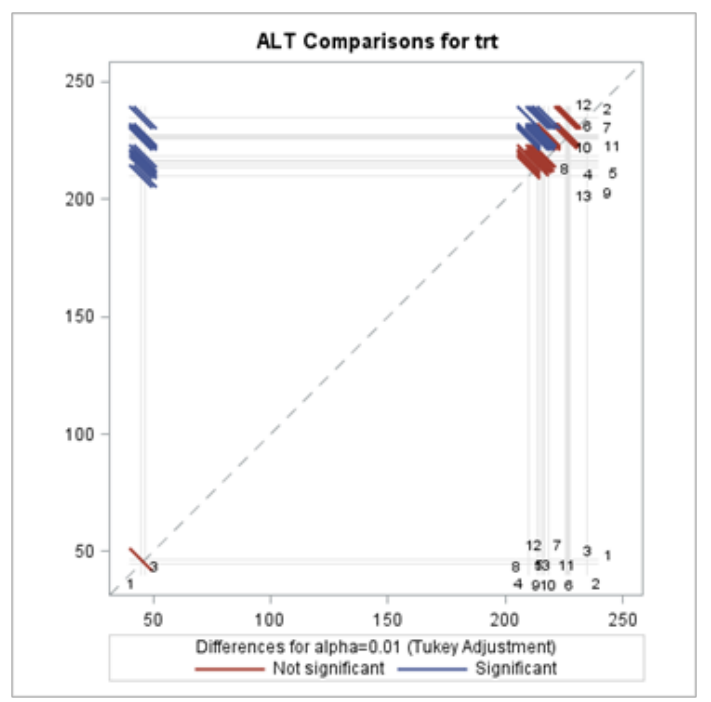

Figure I Treatments comparison for their effects on ALT.

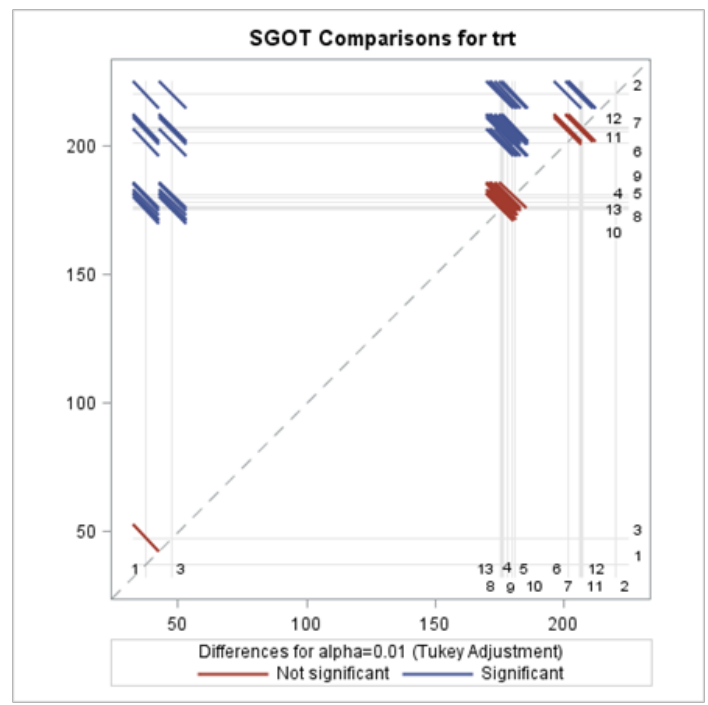

Figure 2 Treatments comparison for their effects on SGOT.

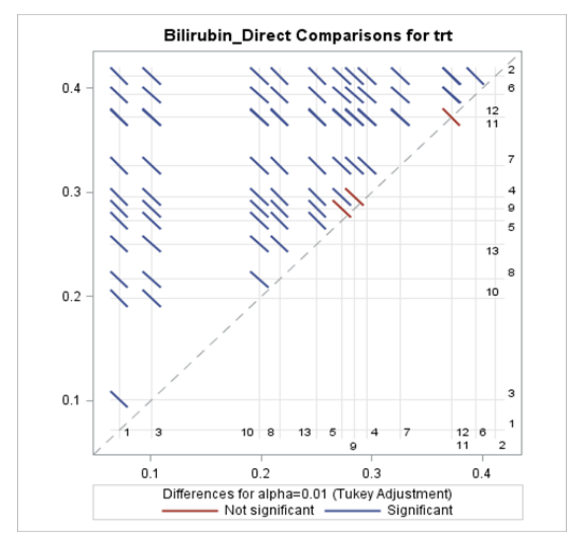

Figure 3 Treatments comparison for their effects on bilirubin.

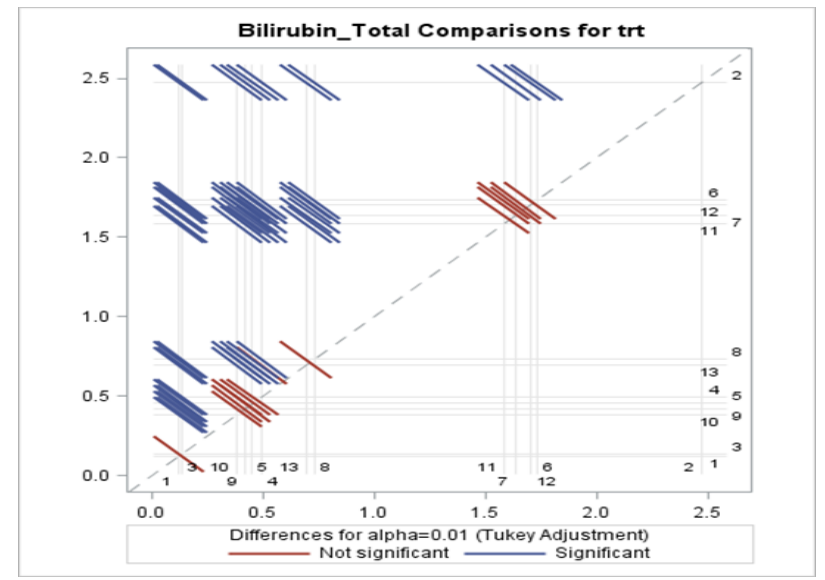

Figure 4 Treatments comparison for their effects on bilirubin total.

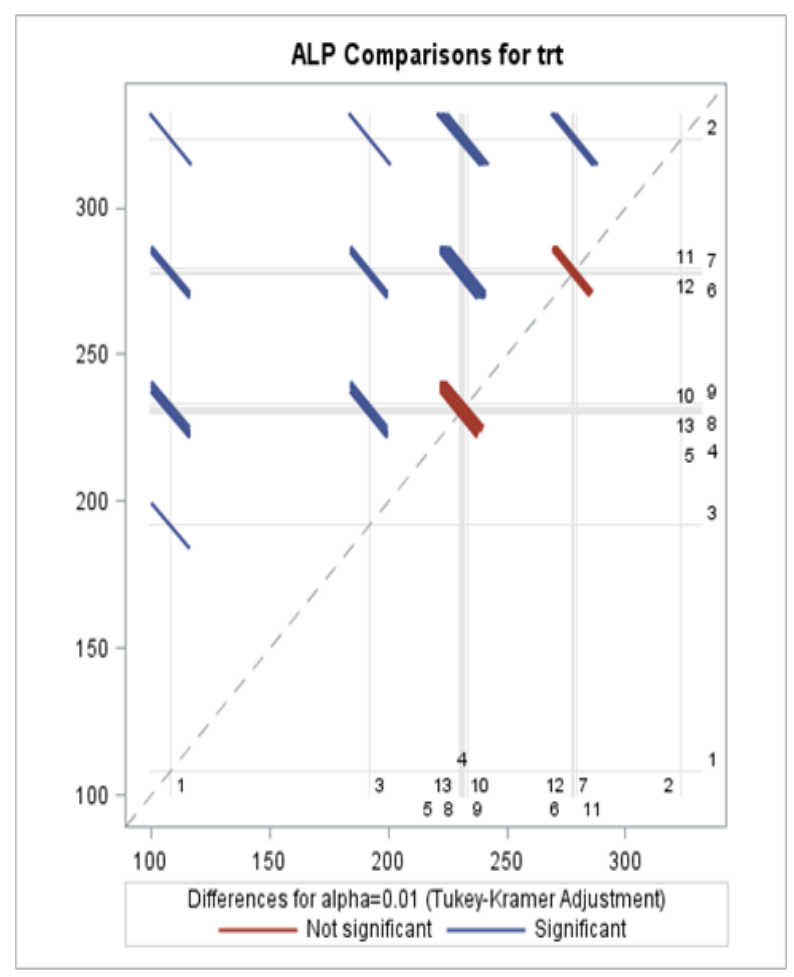

Figure 5 Treatments comparison for their effects on ALP.

Both methanol and hexane crude seed extract of genotypes AF-1 and GF-2 (T-4, 5, 9 and 10) and genotypes Hisar Swarup and Rajendra Saurbha (T-6, 7, 11 and 12) did not differ significantly for bilirubin total (Figure 3) (Table 1) though both the genotypes showed significantly different effect on bilirubin total. When compared with control and $\mathrm{CCL}_{4}$ treated rats treatment 4, 5, 9 and 10 produced most significant effect followed by both the extracts of genotype RF101(T-8 and 13) while T-6, 7, 11 and 12 showed less significant effect on bilirubin total. Figure 4 showed that hexane crude seed extract of genotypes Hisar Swarup (T-11) and Rajendra Saurbha (T-12) did not differ significantly with each other for bilirubin direct. Similarly, no difference was observed in methanol crude seed extract of genotype AF- 1 and GF-2 (T-4 \& 5) and hexane seed extract AF-1 (T-9). Rest of all the treatment combinations is significantly different to each other 
as shown in figure 1a for bilirubin Direct. Treatment 3, 8, 10 and 13 having most significant effect when compared with control while T-6, $\mathrm{T}-11$ and T-12 showed less significant effect on bilirubin direct. Figure 5 showed treatment comparison for ALP. The effect of methanol and hexane extract of Hisar Swarup and Rajendra Saurbha (T-6, 7, 11 and 12) is same on ALP content and both the extract of AF-1, GF-2 and RF-101 also produced similar effect on ALP. Standard drug silymarin was most significant as the value of ALP in silymarin treated rats was near to control i.e. 108.18. Treatment no.4, 5, 8, 9, 10 and 13 were comparatively more effective and significantly differ with remaining other treatments.

A number of biological-pharmacological studies have been undertaken to evaluate the indigenous uses of $F$. vulgare. There are significant number of reports indicating use of fennel extract and isolated compounds for several activities including, hepatoprotective activities. ${ }^{1,5}$ Studies conducted by Özbek et al. ${ }^{7}$ clearly indicated that Foeniculum vulgare essential oil has a potent hepatoprotective action against carbon tetrachloride-induced liver fibrosis in rats. They mentioned essential oil components d-Limonene and $\beta$-Myrcene for their effect on liver. In present investigation methanol and hexane crude seed extracts of popular fennel genotypes were taken for study their hepatoprotective action. Utilization of whole crude extracts of any herbs is expected to be more effective rather than using specific compounds or group of compounds. ${ }^{8}$

In present investigation seed extracts were prepared by cold extraction which expected to contains more phenolics as well as essential and total oil, hence, may be more effective. Earlier studies revealed significant genetic variation in fennel genotypes for essential and fatty oil, its constituents and phenolic contents. ${ }^{6,9}$ Fennel seeds contain 1.5 to $2.0 \%$ essential oil with twenty two constituents belonging to terpenic hydrocarbons, ether, alcohols, aldehydes, Carboxylic acid and diverse functional group. Among ethers, 4-ally anisole and anethol and estragol were the major compounds. Major fatty acids reported in fennel seed oil are petroselinic acid, 10-Nonadecanone, linoleic acid. Fatty acids viz., oleic acid, stearic acid, eicosanoic acid, lenolenic acid and intermediate compounds cyclotetracosan, cyclohexadecan, 10-Nonadecanol were detected in one or other genotypes. ${ }^{9}$ In present study fennel seed extract showed significant reduction in bilirubin content and reduced the elevated levels of all other enzymes supports the usefulness of fennel seeds in hepatoprotective action with significant genotypic variation suggested that specific genotypes may be identified to be use for medicinal significance. Fennel seeds have been used as ingredient of most Indian cuisine and a popular mouth freshener after meal as a traditional practice. The present study supports the health benefit reports of fennel seeds.

\section{Acknowledgements}

The authors are highly thankful to Director, ICAR-NRCSS Ajmer for providing necessary facilities for conducting above study.

\section{Conflict of interest}

The author declares no conflict of interest.

\section{References}

1. Badgujar SB, Patel VV, Bandivdekar AH. Foeniculum vulgare Mill: A Review of its botany, phytochemistry, pharmacology, contemporary application, and toxicology. BioMed Res Int. 2014;2014:842674.

2. Kaur GJ, Arora DS. and phytochemical screening of Anethum graveolens, Foeniculum vulgare and Trachyspermum ammi. BMC Complement Altern Med. 2009;9(1):30.

3. Manonmani R, Khadir AVM. Antibacterial screening on Foeniculum vulgare Mill. Int J Pharma and Bio Sci. 2011;2(4):390-394.

4. Dua A, Mittal A, Gupta S, et al. Bioreactive compounds and antioxidant properties of methanolic extract of fennel (Foeniculum Vulgare). Int Res $J$ Pharm. 2013;4(5):203-208.

5. Agarwal D, Sharma LK, Saxena SN. Anti-microbial properties of fennel (Foeniculum vulgare Mill.) seed extract. Journal of Pharmacognosy and Phytochemistry. 2017;64(4):479-482.

6. Saxena SN, Kakani RK, Rathore SS, et al. Genetic variation in essential oil constituents of fennel (Foeniculum vulgare Mill) germplasm. Journal of Essential Oil Bearing Plants. 2016;19(4):989-999.

7. Özbek H, Ugras S, Dülger H, et al. Hepatoprotective effect of Foeniculum vulgare essential oil. Fitoterapia. 2003;74(3):317-319.

8. Rasoanaivo P, Wright CW, Willcox ML, et al. Whole plant extracts versus single compounds for the treatment of malaria: synergy and positive interactions. Malar J. 2011;10(Supp1 1):S4.

9. Agarwal D. Study on genotypic variation in chemical profiling and medicinal properties of seed spices crops. Ph.D. Udaipur, India: thesis submitted to Pacific University; 2017. 